\title{
First things first: The importance of the preoperative period for neurocognitive outcomes in hypoplastic left heart syndrome
}

\author{
Jennifer M. Lynch, $\mathrm{PhD},{ }^{a}$ and Daniel J. Licht, $\mathrm{MD}^{\mathrm{b}}$
}

\footnotetext{
From the ${ }^{\mathrm{a}} \mathrm{New}$ York University School of Medicine, New York, NY; and ${ }^{\mathrm{b}}$ June and Steve Wolfson Laboratory for Clinical and Biomedical Optics, Neurology and Pediatrics, Philadelphia, Pa.

D.J.L. is supported by grants from the National Institute of Neurological Disorders and Stroke (R01NS72338, RO1 NS060653) and National Institute of Child Health and Human Development (U01 HD087180-01) support from the June and Steve Wolfson Family Foundation.

Disclosures: Authors have nothing to disclose with regard to commercial support.

Received for publication Feb 26, 2016; accepted for publication March 1, 2016

Address for reprints: Daniel J. Licht, MD, June and Steve Wolfson Laboratory for Clinical and Biomedical Optics, Neurology and Pediatrics, 3501 Civic Center Blvd, 10th Floor, Room 10030, Philadelphia, PA 19104 (E-mail: licht@email.chop.edu).

J Thorac Cardiovasc Surg 2016;151:1367-8

$0022-5223 / \$ 36.00$

Copyright (c) 2016 by The American Association for Thoracic Surgery

http://dx.doi.org/10.1016/j.jtcvs.2016.03.001
}

The article by Hansen and colleagues ${ }^{1}$ from the University Hospital Schleswig-Holstein investigates the relationship between perioperative cerebral oxygenation and neurodevelopmental outcomes, intelligence quotient, and cognitive function at approximately 4.5 years. The authors suggest that preoperative, not postoperative, cerebral tissue oxygenation is an important determinant of cognitive development later in life. Although other recent publications have supported the importance of the preoperative period, the correlation between preoperative cerebral tissue oxygenation and neurocognitive outcomes needs to be understood in the context of other risk factors known to be predictive of poorer cognitive function.

The report describes a study of 43 neonates who underwent a Norwood procedure with preoperative and postoperative near-infrared spectroscopy monitoring and subsequently underwent neurodevelopmental testing at 4.5 years. In agreement with previous studies, the authors found that intelligence quotient scores and cognitive functions assessed with the German "Kognitivier Entwicklungstest für das Kindergartenalter" were in the lower normal range. ${ }^{2-4}$ Hansen and colleagues $^{1}$ report that lower preoperative cerebral tissue oxygenation was correlated with poorer neurodevelopmental outcomes at 4.5 years but found no correlation between these developmental outcomes and postoperative recovery of oxygenation.

Monitoring cerebral tissue oxygenation and perfusion in these patients is particularly important because of the high risk for developing hypoxic-ischemic white matter injury. ${ }^{5}$ This type of injury, sometimes referred to as "periventricular leukomalacia," also is seen in infants born prematurely and has been shown to correlate with poor neurodevelopmental outcomes later in life. ${ }^{6-8}$ Thus, low cerebral oxygenation is thought to be a risk factor for poor neurodevelopmental outcomes. However, the exact timing and mechanism behind this risk are still up for debate,

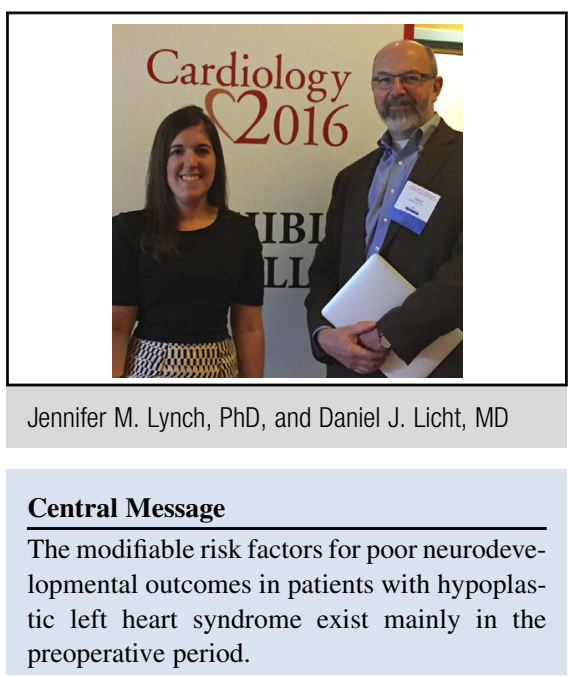

See Article page 1358.

and research is now aimed toward understanding when the brain is most vulnerable to low oxygenation in these patients. The authors' finding that preoperative, and not postoperative, cerebral tissue oxygenation correlates with neurocognitive outcomes is in agreement with recent studies that suggest that the brain is most vulnerable to poor oxygenation during the preoperative period. ${ }^{9-11}$ This increased vulnerability in the preoperative period is likely due to the inability of the cerebral vasculature to accommodate increasing oxygen demand that occurs after birth. Prenatal studies in fetuses with hypoplastic left heart syndrome have shown lower than normal cerebral vascular resistance. ${ }^{12,13}$ This sustained decreased cerebrovascular resistance during fetal life could exhaust the compensatory mechanisms that are needed to increase oxygen delivery in response to increasing demand after birth, resulting in low cerebral tissue oxygenation and, after enough time, hypoxic-ischemic lesions.

The present study from Hansen and colleagues, ${ }^{1}$ along with the other recent studies mentioned, suggest that the modifiable risk factors for poor neurodevelopmental outcomes likely exist in the prenatal and preoperative periods. However, these studies have been limited to single institutions and exclude patients with other comorbidities, such as genetic abnormalities. Larger and more thorough studies and trials investigating the prenatal and preoperative period are essential. To fully appreciate the effect of these modifiable risk factors during the preoperative period, these factors must be understood in the context of patient-specific 
predictors, such as socioeconomic status and genetic abnormalities, which likely have the biggest effect on neurocognitive outcomes later in life. ${ }^{14,15}$ In addition, differences in perioperative care between institutions likely contribute to the variation of incidence, severity, and risk factors for brain injury and poor neurodevelopmental outcome in these patients, making large, multi-institutional studies a necessity.

Hansen and colleagues ${ }^{1}$ demonstrate the vulnerability during the preoperative period in neonates with hypoplastic left heart syndrome by reporting a correlation between preoperative cerebral tissue oxygenation and neurodevelopmental outcomes at 4.5 years. Although the significance of the preoperative period has been suggested previously, large multicenter trials are necessary to understand the effect of the modifiable risk factors in the context of socioeconomic status, perioperative care, and other predictors that likely play the biggest role in neurodevelopmental outcome in this population.

\section{References}

1. Hansen JH, Rotermann I, Logoteta J, Jung O, Dütschke P, Scheewe J, et al. Neurodevelopmental outcome in hypoplastic left heart syndrome: Impact of perioperative cerebral tissue oxygenation of the Norwood procedure. J Thorac Cardiovasc Surg. 2016;151:1358-66.

2. Bellinger D, Wypij D, Rivkin M, DeMaso D, Robertson R, Dunbar-Masterson C, et al. Adolescents With d-transposition of the great arteries corrected with the atrial switch procedure. Pediatr Cardiol. 2011;124:1361-9.

3. Marino B, Lipkin P, Newburger J, Peacock G, Gerdes M, Gaynor J, et al. American Heart Association Congenital Heart Defects Committee, Council on Cardiovascular Disease in the Young, Council on Cardiovascular Nursing, and Stroke Council. Neurodevelopmental outcomes in children with congenital heart disease: evaluation and management: a scientific statement from the American Heart Association. Circulation. 2012;126:1143-72.
4. Shillingford A, Glanzman M, Ittenbach R, Clancy R, Gaynor J, Wernovsky G Inattention, hyperactivity, and school performance in a population of schoolage children with complex congenital heart disease. Pediatrics. 2008;121: 759-67.

5. Mahle W, Tavani F, Zimmerman R, Nicolson S, Galli K, Ganor J, et al. An MRI study on neurological injury before and after congenital heart surgery. Circulation. 2002;106:109-14.

6. Fawer CL, Diebold P, Calame A. Periventricular leucomalacia and neurodevelopmental outcome in preterm infants. Arch Dis Child. 1987;62:30-6.

7. Imamura T, Ariga H, Kaneko M, Watanabe M, Shibukawa Y, Fukuda Y, et al. Neurodevelopmental outcomes of children with periventricular leukomalacia. Pediatr Neonatol. 2013;54:367-72.

8. Miller SP, Ferriero DM, Leonard C, Piecuch R, Glidden DV, Partridge C, et al. Early brain injury in premature newborns detected with magnetic resonance imaging is associated with adverse early neurodevelopmental outcome. J Pediatr. 2005; 147:609-16.

9. Andropoulus D, Hunter J, Nelson D, Stayer S, Stark A, McKenzie E, et al. Brain immaturity is associated with brain injury before and after neonatal cardiac surgery with high-flow bypass and cerebral oxygenation monitoring. J Thorac Cardiovasc Surg. 2010;139:543-56.

10. Lynch JM, Buckley EM, Schwab PJ, McCarthy AL, Winters ME, Busch DR, et al. Time-to-surgery and pre-operative cerebral hemodynamics predict postoperative white matter injury in neonates with hypoplastic left heart syndrome. J Thorac Cardiovasc Surg. 2014;148:2181-8.

11. Anderson B, Ciarleglio A, Salavitabar A, Torres A, Bacha E. Earlier stage 1 palliation is associated with better clinical outcomes and lower costs for neonates with hypoplastic left heart syndrome. J Thorac Cardiovasc Surg. 2015;149: 205-10.

12. Kaltman JR, Di H, Tian Z, Rychik J. Impact of congenital heart disease on cerebrovascular blood flow dynamics in the fetus. Ultrasound Obstet Gynecol. 2005; 25:32-6.

13. Szwast A, Tian Z, McCann M, Soffer D, Rychik J. Comparative analysis of cerebrovascular resistance in fetuses with single-ventricle congenital heart disease. Ultrasound Obstet Gynecol. 2012;40:62-7.

14. Tabbutt S, Nord A, Jarvic G, Bernbaum J, Wernovsky G, Gerdes M, et al. Neurodevelopmental outcomes after staged palliation for hypoplastic left heart syndrome. Pediatrics. 2008;121:476-83.

15. Wernovsky G, Stiles KM, Gauvreau K, Gentles TL, duPlessis AJ, Bellinger D, et al. Cognitive development after the Fontan operation. Circulation. 2000; 102:883-9. 